\title{
Physical Factors Affecting Plasmid DNA Compaction in Stearylamine-Containing Nanoemulsions Intended for Gene Delivery
}

\section{André Leandro Silva ${ }^{1}$, Francisco Alexandrino Júnior ${ }^{1}$, Lourena Mafra Verissimo ${ }^{1}$, Lucymara Fassarella Agnez-Lima ${ }^{2}$, Lucila Carmem Monte Egito ${ }^{3}$, Anselmo Gomes de Oliveira ${ }^{4}$ and Eryvaldo Socrates Tabosa do Egito ${ }^{1, *}$}

1 Laboratório de Sistemas Dispersos (LASID), Universidade Federal do Rio Grande do Norte (UFRN), Natal/RN, Brazil

2 Laboratório de Biologia Molecular e Genômica (LBMG), Departamento de Biologia Celular e Genética, Centro de Biociências, Universidade Federal do Rio Grande do Norte (UFRN), Natal/RN, Brazil

3 Programa de Pós-Graduacao em Ciência e Engenharia de Petróleo, Laboratório de Analises Extratograficas, Centro de Ciências Exatas e Tecnológicas, Universidade Federal do Rio Grande do Norte (UFRN), Natal/RN, Brazil

4 Departamento de Fármacos e Medicamentos, Faculdade de Ciências Farmacêuticas, Universidade Estadual Paulista-Unesp, Rodovia Araraquara-Jaú Km 01, 14801-902, Araraquara, SP, Brazil

* Author to whom correspondence should be addressed; E-Mails: socrates@ufrnet.br or socratesegito@gmail.com; Tel.: +55-84-9431-8816; Fax: +55-84-3342-9808.

Received: 17 May 2012; in revised form: 9 June 2012 / Accepted: 13 June 2012 /

Published: 18 June 2012

\begin{abstract}
Cationic lipids have been used in the development of non-viral gene delivery systems as lipoplexes. Stearylamine, a cationic lipid that presents a primary amine group when in solution, is able to compact genetic material by electrostatic interactions. In dispersed systems such as nanoemulsions this lipid anchors on the oil/water interface confering a positive charge to them. The aim of this work was to evaluate factors that influence DNA compaction in cationic nanoemulsions containing stearylamine. The influence of the stearylamine incorporation phase (water or oil), time of complexation, and different incubation temperatures were studied. The complexation rate was assessed by electrophoresis migration on agarose gel $0.7 \%$, and nanoemulsion and lipoplex characterization was done by Dynamic Light Scattering (DLS). The results demonstrate that the best DNA compaction process occurs after 120 min of complexation, at low temperature
\end{abstract}


$\left(4 \pm 1^{\circ} \mathrm{C}\right)$, and after incorporation of the cationic lipid into the aqueous phase. Although the zeta potential of lipoplexes was lower than the results found for basic nanoemulsions, the granulometry did not change. Moreover, it was demonstrated that lipoplexes are suitable vehicles for gene delivery.

Keywords: gene therapy; stearylamine; cationic lipid nanoemulsions

\section{Introduction}

Medicine is entering a new era of treatments in which doctors will be able to treat not only symptoms, but also the cause of genetic diseases [1]. Genes influence various human diseases in general by coding abnormal proteins that are responsible for the disease or determining susceptibility to environmental agents that induce them. The development of safe and effective carriers for gene delivery has attracted enormous attention in the last decades [2-5].

Recent advances in human genomics and gene delivery systems have made it possible to cure genetic or acquired diseases using gene therapy through the direct modulation of gene expression [4,610]. In this way, gene delivery works where defective genes need to be replaced or pathogenic gene expression needs to be inhibited [9,11]. Moreover, entirely new functions can be added to cells by gene transfer [12], thereby repairing the origin of the disease [6].

Recently, the importance of nanotechnology applied to gene delivery systems [8], in which gene transfer can be achieved by viral or non-viral vehicles has been strongly emphasized [3,9,13-15]. Cationic nanoemulsions have been investigated as non-viral gene carriers in therapeutic gene delivery $[8,10,11,16-18]$ due to the disadvantages related to the use of viral vectors (scale-up control, immunogenicity, oncogenicity, and the limited size of nucleic acid that can be packed) $[8,10,19-21]$. These systems consist of two immiscible liquids containing an oil core (natural or semi-synthetic) stabilized by co-surfactants and cationic surfactants, which are responsible for the positive charge in the droplet surface. The presence of cationic surfactants allows the complexation with the negatively charged DNA via electrostatic interactions [2,8,20-24], resulting in DNA compaction and consequently nanocomplex formation of emulsion/DNA [10]. Besides, cooperative hydrophobic interactions between aliphatic tails might be important in this process [24,25]. Stearylamine, a cationic lipid, is reported to be a suitable cationic surfactant for gene delivery $[10,16,17]$.

The goal of this work was to evaluate the influence of physical factors in the formation of lipoplexes between a cationic nanoemulsion and a plasmidial DNA (pIRES2-EGFP) as a model. Several pieces of evidence lead to the supposition that different temperatures [25,32-34], time of complexation [11,15-17,20], and place of the incorporation phase of the cationic lipid into the systems $[10,25,27]$ might have some influence on the lipoplex formation. 


\section{Experimental Section}

\subsection{Chemicals}

Stearylamine, sorbitan monooleate ( $\left.\operatorname{Span}^{\circledR} 80\right)$, and poly(oxyethylene sorbitan monooleate) (Tween ${ }^{\circledR} 80$ ) were obtained from Sigma Chemical (St. Louis, MO, USA). Medium-chain triglycerides $\left(\right.$ Captex $^{\circledR}$ 355) were donated by Abitech (Columbus, OH, USA). The water used in this study was freshly purified by a Milli-Q Gradient A10 system (Millipore, Molsheim, France). All reagents were used without further purification.

\subsection{Plasmid PIRES2-EGFP DNA ( $p D N A)$}

The plasmid pIRES2-EGFP was amplified in Escherichia coli (strain DH10B) and extracted by MidiPrep [26]. The purity of the plasmidial DNA (pDNA) was measured by OD260/OD280 (1.85 1.90; OD, optical density) and electrophoresis in a $0.7 \%$ agarose gel. pDNA was resuspended in pure water (Milli-Q) and frozen in aliquots.

\subsection{Preparation of Cationic Lipid Nanoemulsions (CLNS)}

The nanoemulsions were produced by the sonication method. Briefly, the aqueous phase components were weighed and mixed with pure water (Milli-Q). The mixture was sonicated for 3 minutes using a probe sonicator at $30 \mathrm{~W}$ (VCX600, Sonics and Materials, Danbury, CT, USA). This mixture was added into the oily phase, which was $50 \mathrm{ng}$ of Captex ${ }^{\circledR} 355$ per $\mathrm{mg}$ of nanoemulsion, and sonicated for $4 \mathrm{~min}$ in an ice-water bath and, then, stored at $4{ }^{\circ} \mathrm{C}$. In order to evaluate possible changes in the physicochemical properties of the nanoemulsions containing stearylamine (CLN) and consequently variations in the complexation efficiency, two different CLNs were formulated, in which the cationic lipid stearylamine was dispersed into the water phase $\left(\mathrm{CLN}_{1}\right)$ or into the oily phase $\left(\mathrm{CLN}_{2}\right)$, as described in Table 1 .

Table 1. Composition of the CLNs: CLN with stearylamine dispersed into aqueous phase $\left(\mathrm{CLN}_{1}\right)$ or CLN with stearylamine dispersed into oily phase $\left(\mathrm{CLN}_{2}\right)$.

\begin{tabular}{ccc}
\hline Component & $\mathbf{C L N}_{\mathbf{1}} \%(\mathrm{w} / \mathrm{w})$ & $\mathbf{C L N}_{\mathbf{2}} \%(\mathrm{w} / \mathrm{w})$ \\
\hline Oily phase & & \\
Captex $^{\circledR} 355(\mathrm{TCM})$ & 5 & 5 \\
Span $^{\circledR} 80$ & 0.8 & 0.8 \\
Stearylamine & - & 0.16 \\
Aqueous phase & & \\
Tween ${ }^{\circledR} 80$ & 1.20 & 1.20 \\
Stearylamine & 0.16 & - \\
Water qsp. & 100 & 100 \\
\hline
\end{tabular}




\subsection{Particle Size and Zeta Potential Analysis}

The mean particle size and zeta potential of the CLN and lipoplexes (at the best pDNA/CLN ratio, which was 2.3 (2.3 ng of pDNA per $1 \mathrm{ng}$ of $\left.\mathrm{CLN}_{1}\right)$ and $0.92\left(0.92 \mathrm{ng}\right.$ of pDNA per $1 \mathrm{ng}$ of $\mathrm{CLN}_{2}$, found by the compaction process assay)) were measured by Dynamic Light Scattering (DLS) and phase analysis light scattering, respectively (Brookhaven ZetaPALS, Holtsville, NY,USA). The formulations were diluted with distilled water by 300 -fold before the measurement.

\subsection{Preparation of PDNA/CLN Complexes}

2.5.1. Influence of the Stearylamine Loading Process at the Water or Oil Phase on the PDNA Compaction Process

To analyze the efficiency in the compaction process of the formulations, both $\mathrm{CLN}_{1}$ and $\mathrm{CLN}_{2}$ were left in contact with pDNA (460 ng/well or $4.60 \mathrm{ng}$ of pDNA per $\mathrm{ng}$ of oil phase of CLN $\mathrm{C}_{1}$ in the case of $\mathrm{pDNA} / \mathrm{CLN}$ ratio 4.60$)$ for $30 \mathrm{~min}$ at room temperature $\left(\mathrm{RT}-25 \pm 2{ }^{\circ} \mathrm{C}\right.$ ) at increasing amounts of CLN ranging from $5 \mu \mathrm{L}$ to $50 \mu \mathrm{L}$. After the preliminary results from such CLN volume variation, a screening was done at a narrow interval from $2 \mu \mathrm{L}$ to $10 \mu \mathrm{L}$ (Table 2). Although the volume inside the well varied, the pDNA concentration remained constant at $460 \mathrm{ng} /$ well. In fact, because the full lipoplex volume will be used for the gel running and the volume variation did not affect the pDNA state by itself, the gel running would present the same bend intensity if no lipoplex were formed. It is important to note that CLN has $5 \%(\mathrm{w} / \mathrm{w})$ of oil. This corresponds at $50 \mathrm{ng}$ of Captex ${ }^{\circledR} 355$ per $1 \mathrm{mg}$ (or $1 \mu \mathrm{L}$ ) of nanoemulsion. Because the oil content has a direct relationship with the number of droplets into the CLN system, and by consequence the state in which the pDNA was found into the media, this value was used to establish the pDNA/CLN ratio.

Table 2. Study concentration of CLN and its corresponding pDNA/CLN ratio.

\begin{tabular}{cc}
\hline CLN $(\mu \mathbf{L})$ & pDNA(ng)/CLN(ng oil phase) ratio \\
\hline $\mathbf{2}$ & 4.60 \\
$\mathbf{4}$ & 2.30 \\
$\mathbf{5}$ & 1.84 \\
$\mathbf{6}$ & 1.53 \\
$\mathbf{7}$ & 1.31 \\
$\mathbf{8}$ & 1.15 \\
$\mathbf{9}$ & 1.02 \\
$\mathbf{1 0}$ & 0.92 \\
\hline
\end{tabular}

\subsubsection{Influence of the Time of Complexation}

Because $\mathrm{CLN}_{1}$ presented a better compaction process compared to $\mathrm{CLN}_{2}$, different times of contact between pDNA and $\mathrm{CLN}_{1}$ (at the best $\mathrm{pDNA} / \mathrm{CLN}_{1}$ ratio, found by the compaction process assay) were assessed at $0,15,30,60,90$, and $120 \mathrm{~min}$. This experiment was conducted at RT. 
2.5.3. Influence of the Temperature on the Lipoplex Formation

To analyze the influence of temperature in the compaction process assay, three different temperatures were evaluated: RT, $37 \pm 2{ }^{\circ} \mathrm{C}$ and $4 \pm 1{ }^{\circ} \mathrm{C}$ (ice-bath). Again, $\mathrm{CLN}_{1}$ formulation was used as the reference due to the results obtained in the compaction process assay. pDNA (4.60 ng of per ng of internal phase of $\mathrm{CNL}_{1}$ ) was mixed and left in contact for $30 \mathrm{~min}$.

\subsection{Efficiency of Complexation by Electrophoresis Assay}

The complexes were loaded onto $0.7 \%$ agarose gel containing ethidium bromide $(0.5 \mathrm{mg} / \mathrm{mL})$ using $40 \mathrm{mM}$ Tris acetate and $1 \mathrm{mM}$ EDTA as buffer. Gel was run at $80 \mathrm{mV}$ for $60 \mathrm{~min}$ and the trapping efficiency of pDNA by CLNs was determined as the DNA was no longer accessible to ethidium bromide intercalation by the assay of gel electrophoresis [20].

\section{Results and Discussion}

\subsection{Particle Size and Zeta-Potential Characteristics}

DLS analysis of CLNs and lipoplexes ensured that the produced systems were at nanoscale dimensions (Table 3). It is important to note that the pDNA in stock solution-presented a mean particle size of $52.2 \pm 0.6 \mathrm{~nm}$. It should be emphasized that this size is given as a purpose of comparison with the CLN size. In fact, hydrodynamic volume (which is measured by the DLS) changes according the kind of coiled in which the plasmid has been presented.

Table 3. Characterization (Size, Polydispersity Index (PI) and Zeta Potential) of CLNs and lipoplexes $\left(\mathrm{CLN}_{1}-1.60 \mathrm{pDNA} / \mathrm{CLN}_{1}\right.$ ratio; $\mathrm{CLN}_{2}-0.64 \mathrm{pDNA} / \mathrm{CLN}_{2}$ ratio).

\begin{tabular}{cccc}
\hline Formulation & Size $(\mathbf{n m}) \pm \mathbf{S D}$ & PI $( \pm \mathbf{S D})$ & Zeta Potential $(\mathbf{m V}) \pm$ SD \\
\hline $\mathbf{C L N}_{\mathbf{1}}$ & $195.1 \pm 2.9$ & $0.185 \pm 0.015$ & $41.9 \pm 4.3$ \\
$\mathbf{C L N}_{\mathbf{1}}$-lipoplex & $200.7 \pm 4.2$ & $0.177 \pm 0.027$ & $22.5 \pm 3.4$ \\
$\mathbf{C L N}_{\mathbf{2}}$ & $199.1 \pm 4.2$ & $0.185 \pm 0.004$ & $39.6 \pm 4.1$ \\
$\mathbf{C L N}_{\mathbf{2}}$-lipoplex & $204.0 \pm 0.2$ & $0.213 \pm 0.010$ & $25.7 \pm 0.3$ \\
\hline
\end{tabular}

CLNs presented particle sizes smaller than $200 \mathrm{~nm}$, for both $\mathrm{CLN}_{1}$ and $\mathrm{CLN}_{2}$. After lipoplex formation, no significant increase in droplet size was found for either $\mathrm{CLN}_{1}$ or $\mathrm{CLN}_{2}$, probably because the pDNA was not only adsorbed, but also condensed on the droplet surface, and its negligible concentration (460 $\mathrm{ng}$ ) does not induce enough surface volume charge to improve the nanoemulsion droplet size.

The Polydispersity Index (PI) was around 0.2 for all formulations (Table 3). Moreover, the droplet size distribution of the systems was quite homogeneous and not influenced by the lipoplex formation generated between pDNA and CLN.

As can be observed by the positive values of zeta potential, stearylamine gives a positive charge to the droplet surface. Zeta potential results were around $+40 \mathrm{mV}$ for both $\mathrm{CLN}_{1}$ and $\mathrm{CLN}_{2}$, which not only provides enough positive charges for lipoplex formation, but also provides CLN stability by 
electrostatic repulsion. When lipoplexes were formed, zeta potential decreased (Table 3). This could be explained by the negative charge from the pDNA being added to the system, thereby turning the zeta potential less positive.

This result is quite interesting because although the complexation study revealed that $\mathrm{CLN}_{1}$, which has stearylamine at the outermost oil/water interface, possesses different behavior concerning lipoplex formation compared to $\mathrm{CLN}_{2}$, which has stearylamine at the innermost oil/water interface, both products presented the same zeta potential. This is probably due to the migration of the stearylamine from the innermost to the outermost interface induced by the dilution process of 300 fold, mandatory for this assay.

\subsection{Effects of Stearylamine Loading Phase on the pDNA/CLN Complexation}

Although at different $\mathrm{pDNA} / \mathrm{CLN}$ ratios, $100 \%$ of DNA compaction was achieved by diluting the pDNA solution with both $\mathrm{CLN}_{1}$ and $\mathrm{CLN}_{2}$. The presence of the CLN droplets at pDNA/CLN ratio above 2.30 for $\mathrm{CLN}_{1}$ and above 0.92 for $\mathrm{CLN}_{2}$ (Table 2), in which a high amount of droplets exists, induces totally complex formation and no free pDNA could be seen in the gel bend. Complexation is possible due to electrostatic interactions between the positively charged stearylamine head group (which is located on the oil/water interface) and the negatively charged phosphate anchor from the pDNA $[5,6,8,16]$.

Matulis et al. have demonstrated by thermodynamic assays that condensation is dependent on DNA concentration [25]. In this way, from the data set revealed by $\mathrm{CLN}_{1}, 4 \mu \mathrm{L}$ of $\mathrm{CLN}_{1}$ was enough to completely condense the genetic material. Figure 1 shows that by increasing the DNA/CLN ratio higher than $2.30 \mathrm{pDNA}^{-C_{L N}}$ ratio, no free pDNA can be seen, which means that the $460 \mathrm{ng}$ of pDNA was completely condensed with $4 \mu \mathrm{L}$ of $\mathrm{CLN}_{1}$.

It is known that polyethylene glycol (PEG) domains present in Tween ${ }^{\circledR} 80$ avoid oil droplet aggregation in emulsions [10]. This is also related to a steric effect (because of those mentioned PEG domains) for Tween ${ }^{\circledR} 80$, which could make the entrapment of the pDNA molecule [27] difficult. When stearylamine is placed into the aqueous phase, Tween $80^{\circledR}$ might be placed on the oil/water surface and the stearylamine could be located more externally at the outermost surface of the drop, minimizing the furtive effect from PEG. On the other hand, when stearylamine is loaded into the oil phase, the charge is there, but located in the innermost regions of the drop, which allows the steric effect from PEG to participate, and makes the complete complexation of pDNA difficult. It is important to note that, in this case, a probable partition of stearylamine into the two phases was negligible because the steric effect, which is dependent on the phase where stearylamine was placed, was demonstrated. This is in agreement with the works of Matulis et al., who described a binding model where cationic head groups are near DNA phosphates while the aliphatic tails stand perpendicular to the DNA surface [25]. 
Figure 1. Influence of the $\mathrm{CLN}_{1}$ amount on the compaction of pDNA.

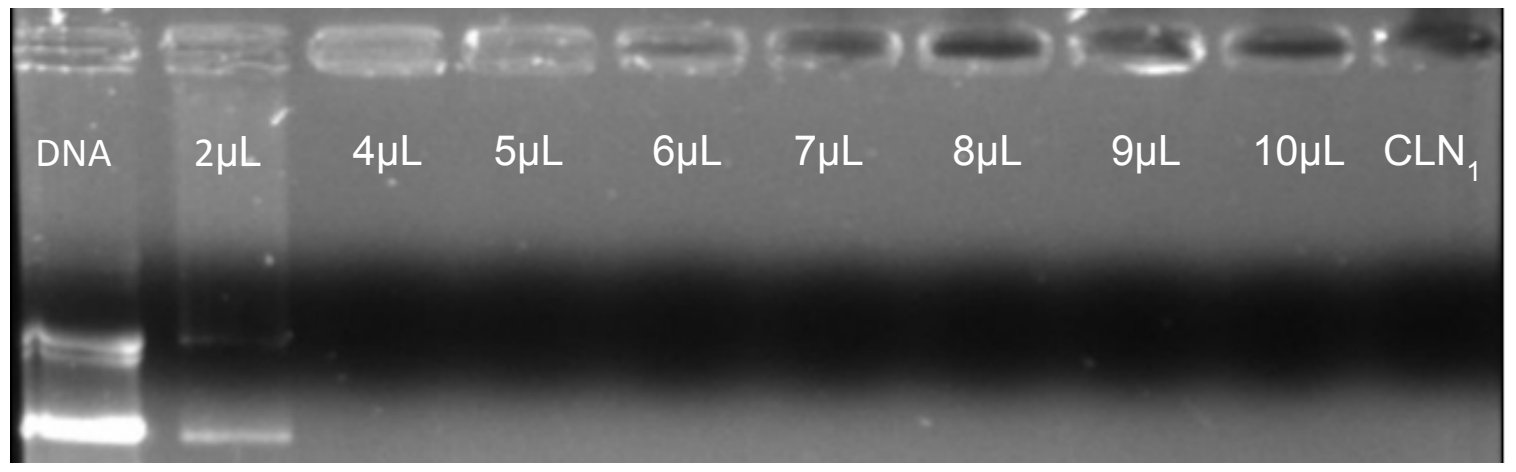

Concerning $\mathrm{CLN}_{2}$, it was found that a larger amount of CLN was necessary to compact the same quantity of pDNA compared to $\mathrm{CLN}_{1}$ (Figure 2). In this case, around $10 \mu \mathrm{L}$ of $\mathrm{CLN}_{2}$ ( $0.92 \mathrm{pDNA} / \mathrm{CLN}_{2}$ ratio) was necessary to completely compact the $460 \mathrm{ng}$ of the genetic material, which represents more than twice the volume of $\mathrm{CLN}_{1}$.

Figure 2. Influence of the $\mathrm{CLN}_{2}$ amount on the compaction of pDNA.

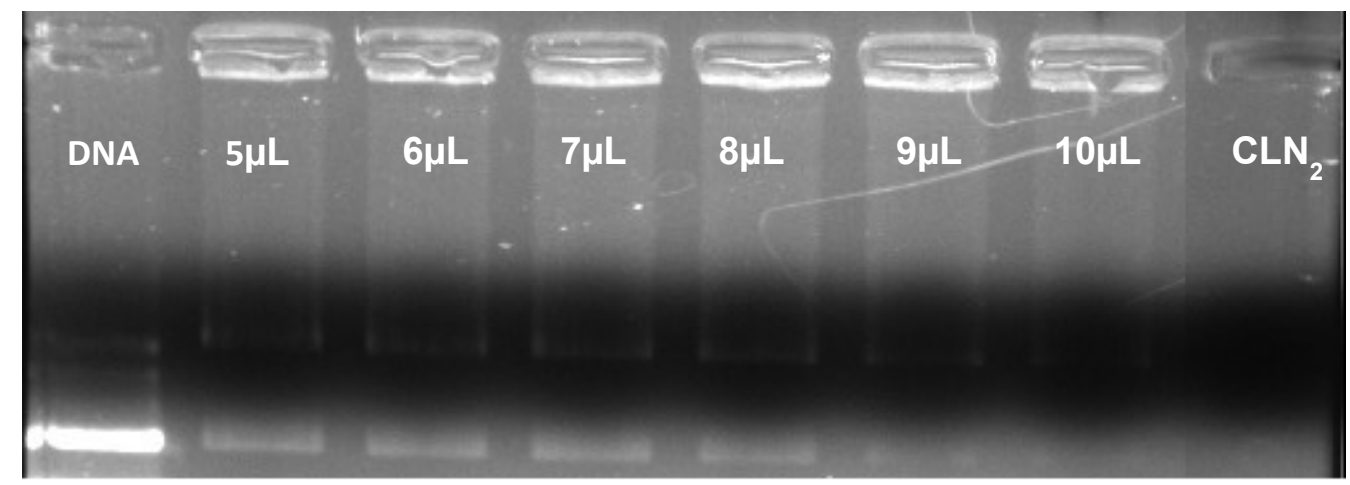

Most of the time, complexation is done by adsorption of the genetic material to the cationic system by electrostatic interaction [16,17,19-21]. However, other methods could be used to ensure that the genetic material is loaded on the carrier. Nanoencapsulation of genetic material is another related approach [28]. This was demonstrated by Badea et al. [29], who produced nanoparticles where the genetic material was put into the formulation during the manufacturing process. Also, Kwon et al. [23] previously prepared nanoemulsions, added pDNA, and sonicated the mixtures in order to form lipoplexes. All these approaches are in agreement with our results. Moreover, a combination of two mechanisms, named electrostatic interaction and nanoencapsulation assembly, can play an important role in the pDNA complexation in CLN systems.

\subsection{Time Effect on pDNA/CLN Complexation}

Concerning non-viral gene delivery systems, the literature reports different times of complexation. It seems that there are no rules governing this variation and many different times are related to the complete complexation of genetic material. Time of complexation changes not only concerning the kind of genetic material, but also the different pharmaceutical systems. Tang et al. [20] worked with 
two complexation times. They started complexing for $30 \mathrm{~min}$ and then reduced the time for $10 \mathrm{~min}$ of incubation at RT. Kim et al. [14] did nanoparticle complexing of pDNA for 1 hour at RT but Munier et al. [19] used $10 \mathrm{~min}$ as the time of complexation for their nanoparticles. Other authors working with nanoparticles have described achieving complete complexation in just 5 min [2,3,21]. Teixeira et al. [16] associated oligonucleotides with cationic nanoemulsions for $12 \mathrm{~h}$. Martini et al. [17] used a similar system and associated the genetic material for $30 \mathrm{~min}$ and Bruxel et al. [11] for just 15 min. Concerning liposomes, there is also no pattern of complexation time [5,30,31]. Zhang et al. [15] evaluated complexation of both pDNA and siRNA for 20 min using a unique system and found different ratios of complexation according to the kind of genetic material. Therefore, it could be seen that each researcher chooses the best time of association experimentally, according to the kind of both formulation and genetic material [11,15-17,20].

This study reveals that for CLN $120 \mathrm{~min}$ is the best time of complexation (Figure 3). It was observed that after just adding the pDNA in contact with the CLN, lipoplexes were immediately generated in spite of the important amount of DNA that remained uncomplexed. With the time increasing, the intensity of the bend diminished and, after $120 \mathrm{~min}$, free pDNA was no longer observed, meaning that $100 \%$ of the pDNA was complexed and condensed.

Figure 3. Time complexation of pDNA by $\mathrm{CLN}_{1}\left(2.30 \mathrm{pDNA}^{\mathrm{CLN}} \mathrm{CL}_{1}\right.$ ratio).

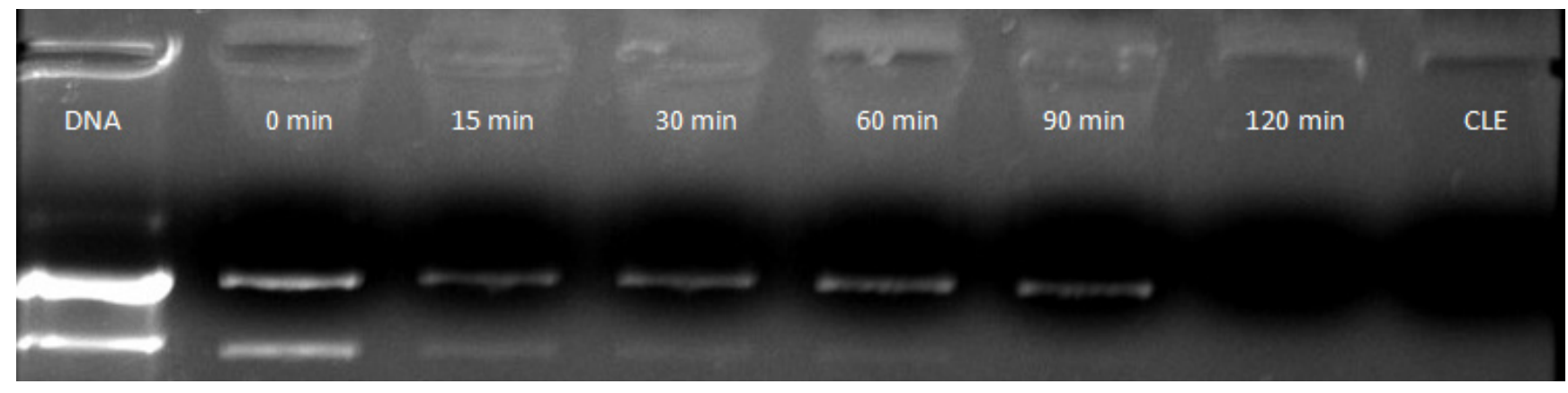

\subsection{Effects of the Environmental Temperature on the pDNA/CLN Complexation}

Usually, complexation is done at RT $[14,16,17,19,20]$. In this study a comparison of three different temperatures [RT, "cold" temperature $\left(4^{\circ} \mathrm{C}\right)$, and "hot" temperature $\left.\left(37^{\circ} \mathrm{C}\right)\right]$ was performed to observe whether there is any influence of temperature on the complexation efficiency (Figure 4). It was observed that the same amount of pDNA in the same time of complexation had differences in the complexation range. Naked pDNA was also analyzed at the three different temperatures, as a control, to ensure that there would be no difference in the gel visualization when the pDNA was maintained at different temperatures. 
Figure 4. Influence of the environmental temperature on (a) naked pDNA ( $1 \mu \mathrm{g}$ per well, with a total mass of pDNA of $1,000 \mathrm{ng}$ ) and (b) pDNA/CLN 1 complex formation (158.75 $\mathrm{ng}$ of $\mathrm{pDNa}$ per $\mu \mathrm{L}$ of $\mathrm{CNL}_{1}$, with a total mass of pDNA of $1,270 \mathrm{ng}$ ).

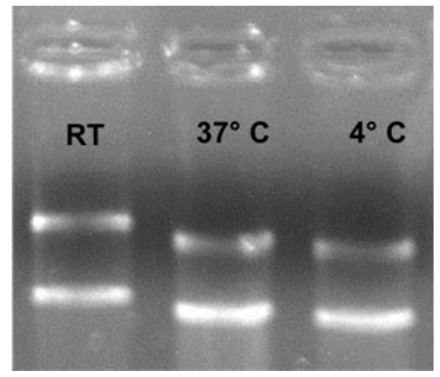

(a)

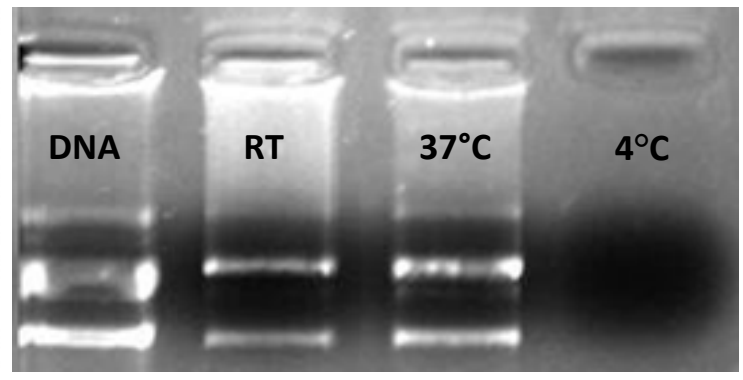

(b)

As shown in Figure 4, at RT some compaction is achieved. However, it seems that by increasing the temperature to $37{ }^{\circ} \mathrm{C}$ less pDNA is packed. On the other hand, at $4{ }^{\circ} \mathrm{C}$ all the genetic material was packed by the $\mathrm{CLN}_{1}$. A crucial point is that at this temperature, naked DNA, although at lower mass concentration (1,000 ng), presented a bend on the running gel (Figure 4a). The reason is that, according to the temperature, plasmids should assume, more or less, the supercoiled form [32,33]. In fact, at high temperature, the pDNA assumes more relaxed forms and gains more volume. Inversely, at cold temperature it assumes less volume and becomes supercoiled [34] and more pDNA can be packed by the CLN. Furthermore, Matulis et al. demonstrated that at a higher temperature, the interaction between the cationic lipids with DNA is slightly weaker, due to the less favorable electrostatic and hydrophobic entropies and electrostatic enthalpy [25]. For a clinical approach, it is important to note that the transfection efficiency is highly dependent on the quality and conformation of the used DNA [35].

\section{Conclusions}

The use of non-viral gene delivery systems for gene therapy can solve most of the drawbacks related to viral vectors such as any serious side effects related to its safety and the host immune and inflammatory responses. However, clinical application of this approach requires the development of safe and efficient delivery vehicles.

Developing non-viral gene delivery systems is not an easy task and a large number of variations can influence the final pharmaceutical and nanotechnological systems. Despite the fact that models of the interactions between cationic lipids and genetic materials have been developed, this process is still poorly understood. In this work it has been shown that temperature, cationic lipid phase incorporation, and time of complexation all play important roles in the formation of lipoplexes. In fact, these parameters could block the genetic carrier from complexing with the pDNA in order to form lipoplexes, which is mandatory for gene delivery. Moreover, the results presented here allow us to speculate that the stearylamine containing cationic nanoemulsions would be a suitable non-viral vehicle for gene therapy. However, further studies such as cytotoxicity, in vitro, and in vivo transfection assays are necessary to confirm this hypothesis. 


\section{Acknowledgments}

We would like to thank Capes for the Financial Support and Prof. Elias Fattal from the University of Paris XI for the funding support. The authors were also grateful to Glenn Hawes, from the University of Georgia, American Language Program, for editing this manuscript.

\section{Conflict of Interest}

The authors declare no conflict of interest.

\section{References}

1. Rolland, A.; Sullivan, S.M. Pharmaceutical Gene Delivery System; Marcel Dekker: New York, NY, USA, 2003.

2. Dai, Z.; Gjetting, T.; Mattebjerg, M.A.; Wu, C.; Andresen, T.L. Elucidating the Interplay between DNA-condensing and Free Polycations in Gene Transfection through a Mechanistic Study of Linear and Branched Pei. Biomaterials 2011, 32, 8626-8634.

3. Yue, Y.; Jin, F.; Deng, R.; Cai, J.; Dai, Z.; Lin, M.C.M.; Kung, H.F.; Mattebjerg, M.A.; Andresen, T.L.; Wu, C. Revisit Complexation between DNA and Polyethylenimine - Effect of Length of Free Polycationic Chains on Gene Transfection. J. Control. Release 2011, 152, 143-151.

4. Geusens, B.; Strobbe, T.; Bracke, S.; Dynoodt, P.; Sanders, N.; Van Gele, M.; Lambert, J. Lipidmediated Gene Delivery to the Skin. Eur. J. Pharm. Sci. 2011, 43, 199-211.

5. Ramezani, M.; Khoshhamdam, M.; Dehshahri, A.; Malaekeh-Nikouei, B. The Influence of Size, Lipid Composition and Bilayer Fluidity of Cationic Liposomes on the Transfection Efficiency of Nanolipoplexes. Colloid Surface B 2009, 72, 1-5.

6. Liu, F.; Huang, L. Development of Non-viral Vectors for Systemic Gene Delivery. J. Control. Release 2002, 78, 259-266.

7. De Ilarduya, C.T.; Sun, Y.; Duezguenes, N. Gene Delivery by Lipoplexes and Polyplexes. Eur. J. Pharm. Sci. 2010, 40, 159-170.

8. Verissimo, L.M.; Agnez Lima, L.F.; Monte Egito, L.C.; de Oliveira, A.G.; Tabosa do Egito, E.S. Pharmaceutical Emulsions: A new Approach for Gene Therapy. J. Drug Targeting 2010, 18, 333-342.

9. Kapoor, M.; Burgess, D.J.; Patil, S.D. Physicochemical Characterization Techniques for Lipid Based Delivery Systems for Sirna. Int. J. Pharm. 2012, 427, 35-57.

10. Liu, C.-H.; Yu, S.-Y. Cationic Nanoemulsions as Non-viral Vectors for Plasmid DNA Delivery. Colloid. Surface. B. 2010, 79, 509-515.

11. Bruxel, F.; Cojean, S.; Bochot, A.; Teixeira, H.; Bories, C.; Loiseau, P.M.; Fattal, E. Cationic Nanoemulsion as a Delivery System for Oligonucleotides Targeting Malarial Topoisomerase ii. Int. J. Pharm. 2011, 416, 402-409.

12. Cecchi, C.R.; Dagnaes-Hansen, F.; Gissel, H.; Gothelf, A.; Jakobsen, M.; Hansen, B.H.; Frystyk, J.; Oliveira, N.A.J.; Higuti, E.; Bartolini, P.; Peroni, C.N.; Jensen, T.G. Non-viral Gene Transfer to Skin, Muscle and Liver for Expression of Growth Hormone. Hum. Gene Ther. 2011, 22, A86-A86. 
13. Castilho, L.R.; Moraes, Â.M.; Augusto, E.F.P.; Butler, M. Animal Cell Technology: From Biopharmaceuticals to Gene Therapy; Taylor \& Francis: New York, NY, USA, 2008.

14. Kim, I.S.; Lee, S.K.; Park, Y.M.; Lee, Y.B.; Shin, S.C.; Lee, K.C.; Oh, I.J. Physicochemical Characterization of Poly(l-lactic acid) and Poly(d,l-lactide-co-glycolide) Nanoparticles with Polyethylenimine as Gene Delivery Carrier. Int. J. Pharm. 2005, 298, 255-262.

15. Zhang, Y.; Li, H.; Sun, J.; Gao, J.; Liu, W.; Li, B.; Guo, Y.; Chen, J. Dc-chol/Dope Cationic Liposomes: A Comparative Study of the Influence Factors on Plasmid Pdna and Sirna Gene Delivery. Int. J. Pharm. 2010, 390, 198-207.

16. Teixeira, H.; Rosilio, V.; Laigle, A.; Lepault, J.; Erk, I.; Scherman, D.; Benita, S.; Couvreur, P.; Dubernet, C. Characterization of Oligonucleotide/Lipid Interactions in Submicron Cationic Emulsions: Influence of the Cationic Lipid Structure and the Presence of Peg-lipids. Biophys. Chem. 2001, 92, 169-181.

17. Martini, E.; Fattal, E.; de Oliveira, M.C.; Teixeira, H. Effect of Cationic Lipid Composition on Properties of Oligonucleotide/Emulsion Complexes: Physico-chemical and Release Studies. Int. J. Pharm. 2008, 352, 280-286.

18. Wu, H.L.; Ramachandran, C.; Bielinska, A.U.; Kingzett, K.; Sun, R.; Weiner, N.D.; Roessler, B.J. Topical Transfection using Plasmid DNA in a Water-in-oil Nanoemulsion. Int. J.Pharm. 2001, 221, 23-34.

19. Munier, S.; Messai, I.; Delair, T.; Verrier, B.; Ataman-Onal, Y. Cationic pla nanoparticles for DNA Delivery: Comparison of Three Surface Polycations for DNA Binding, Protection and Transfection Properties. Colloid. Surface. B. 2005, 43, 163-173.

20. Tang, R.; Ji, W.; Wang, C. Synthesis and Characterization of New Poly(ortho ester amidine) Copolymers for Non-viral Gene Delivery. Polymer 2011, 52, 921-932.

21. Yue, Y.A.; Jin, F.; Deng, R.; Cai, J.G.; Chen, Y.C.; Lin, M.C.M.; Kung, H.F.; Wu, C. Revisit Complexation between DNA and Polyethylenimine - effect of Uncomplexed Chains Free in the Solution Mixture on Gene Transfection. J. Control. Release 2011, 155, 67-76.

22. Nam, H.Y.; Park, J.H.; Kim, K.; Kwon, I.C.; Jeong, S.Y. Lipid-based Emulsion System as NonViral Gene Carriers. Arch. Pharm. Res. 2009, 32, 639-646.

23. Kwon, S.M.; Nam, H.Y.; Nam, T.; Park, K.; Lee, S.; Kim, K.; Kwon, I.C.; Kim, J.; Kang, D.; Park, J.H.; Jeong, S.Y. In Vivo Time-dependent Gene Expression of Cationic Lipid-based Emulsion as a Stable and Biocompatible Non-viral Gene Carrier (vol 128, pg 89, 2008). J. Control. Release 2009, 140, 74-74.

24. Marty, R.; N'Soukpoe-Kossi, C.N.; Charbonneau, D.; Weinert, C.M.; Kreplak, L.; Tajmir-Riahi, H.-A. Structural Analysis of DNA Complexation with Cationic Lipids. Nucl. Acid. Res. 2009, 37, 849-857.

25. Matulis, D.; Rouzina, I.; Bloomfield, V.A. Thermodynamics of Cationic Lipid Binding to DNA and DNA Condensation: Roles of Electrostatics and Hydrophobicity. J Am Chem Soc. 2002, 124, 7331-7342.

26. Sambrook, J.; Russell, D.W. Molecular Cloning: A Laboratory Manual, 3rd ed.; Cold Spring Harbor Laboratory Press: New York, 2001; Volume 1. 
27. Kim, T.W.; Chung, H.; Kwon, I.C.; Sung, H.C.; Jeong, S.Y. Optimization of Lipid Composition in Cationic Emulsion as in Vitro and in Vivo Transfection Agents. Pharmaceut. Res. 2001, 18, 54-60.

28. Vonarbourg, A.; Passirani, C.; Desigaux, L.; Allard, E.; Saulnier, P.; Lambert, O.; Benoit, J.-P.; Pitard, B. The Encapsulation of DNA Molecules within Biomimetic Lipid Nanocapsules. Biomaterials 2009, 30, 3197-3204.

29. Badea, I.; Wettig, S.; Verrall, R.; Foldvari, M. Topical Non-invasive Gene Delivery Using Gemini Nanoparticles in Interferon-gamma-deficient Mice. Eur. J. Pharm. Biopharm. 2007, 65, 414-422.

30. Hirsch-Lerner, D.; Zhang, M.; Eliyahu, H.; Ferrari, M.E.; Wheeler, C.J.; Barenholz, Y. Effect of "Helper Lipid" on Lipoplex Electrostatics. BBA-Biomembranes 2005, 1714, 71-84.

31. Zuidam, N.J.; Barenholz, Y. Electrostatic and Structural Properties of Complexes Involving Plasmid DNA and Cationic Lipids Commonly Used for Gene Delivery. BBA-Biomembranes 1998, 1368, 115-128.

32. TseDinh, Y.C.; Qi, H.Y.; Menzel, R. DNA Supercoiling and Bacterial Adaptation: Thermotolerance and Thermoresistance. Trends Microbiol. 1997, 5, 323-326.

33. Schleef, M. Plasmids for Therapy and Vaccination. Wiley-VCH: New York, NY, USA, 2001.

34. Witz, G.; Stasiak, A. DNA Supercoiling and Its Role in DNA Decatenation and Unknotting. Nucl. Acid. Res. 38, 2119-2133.

35. Walther, W.; Stein, U.; Voss, C.; Schmidt, T.; Schleef, M.; Schlag, P.M. Stability Analysis for Long-term Storage of Naked DNA: Impact on Nonviral In Vivo Gene Transfer. Anal. Biochem. 2003, 318, 230-235.

(C) 2012 by the authors; licensee MDPI, Basel, Switzerland. This article is an open access article distributed under the terms and conditions of the Creative Commons Attribution license (http://creativecommons.org/licenses/by/3.0/). 